\title{
An Overview of Laser-assisted Bioprinting (LAB) in Tissue Engineering Applications
}

Reiza Dolendo Ventura

Independent Researcher, Alumnus University of the Philippines, Los Baños, Laguna, Philippines
Received May 14, 2021

Accepted June 10, 2021

\section{Correspondence}

Reiza Dolendo Ventura

Alumnus University of the Philippines Los Baños, 19-I Domingo Guevara, Brgy, Highway Hills, Mandaluyong City 1550, Metro Manila, Philippines Tel.: +63-9064575963

Fax: +63-02-85841612

E-mail: reizaventurađyahoo.com

(C) Korean Society for Laser Medicine and Surgery

(c) This is an open access article distributed under the terms of the Creative Commons Attribution NonCommercial License (http://creativecommons.org/ licenses/by-nc/4.0) which permits unrestricted noncommercial use, distribution, and reproduction in any medium, provided the original work is properly cited.
Biological tissues and organs are composed of different arrays of cells, biochemical cues, and extracellular matrices arranged in a complex microarchitecture. Laser-Assisted Bioprinting (LAB) is an emerging and promising technology that is reproducible with high accuracy that can be used for fabricating complex bioengineered scaffolds that mimic tissues and organs. The LAB process allows researchers to print intricate structural scaffolds using cells and different biomaterials essential for facilitating cell-scaffold interaction and to induce tissue and organ regeneration which cannot be achieved in a traditional scaffold fabrication. This process can fabricate artificial cell niches or architecture without affecting cellular viability and material integrity. This review tackles the basic principles and key aspects of Laser-Assisted Bioprinting. Recent advances, limitations, and future perspectives are also discussed.

\section{Key words}

Laser assisted bioprinting; Bioprinting; Laser; Tissue engineering; Bioinks 


\section{INTRODUCTION}

The demand for defective tissues and organs is high due to limited donors as allogeneic and autologous grafts are still the gold standard for organ and tissue regeneration. A top-down approach is a traditional and most common method in fabricating 3D tissue scaffolds that involves seeding cells into a porous scaffold that provides structural and functional cues to facilitate tissue regeneration. However, it is not applicable for tissues and organs with complex structure and function as it does not provide a uniform cell distribution, low cell density, slow vascularization, and limitation in the diffusion of nutrients and byproducts. To address these issues, three-dimensional (3D) bioprinting was utilized and explored for the fabrication of tissues and organs using biomaterials, specific cells, and bioactive growth factors to promote tissue regeneration and effectively restore its functions. 3D bioprinting is the process of fabricating a bio-engineered construct in a layer-by-layer fashion based on the spatial organization of native tissues and organs.'

Laser-assisted bioprinting ( $L A B$ ) is a promising technology for the fabrication of complex cell-laden 2D biomaterials in tissue engineering. Moreover, when implanted in vivo, LAB scaffolds provide a homogeneously distributed cell-laden scaffold for better host tissue integration, lower implant rejection risk, and uniform tissue growth. It allows fabricating a homogeneously cell-distributed scaffold and better vascularization that cannot be achieved by manual seeding on a traditional engineered scaffold. It is a non-contact and nozzle-free bioprinting method that overcomes the downside of other bioprinting methods such as clogging of print heads, or capillaries caused by high viscosity, cell agglomeration or ink drying. ${ }^{2}$

\section{LASER ASSISTED BIOPRINTING (LAB)}

The laser-assisted bioprinting ( $L A B$ ) process is direct writing based on laser-induced forward transfer (LIFT) technology initially developed for high-resolution patterning of metals for computer chip fabrication. ${ }^{3}$ It consists of 3 main parts as depicted in Fig. 1; a pulsed laser source, a ribbon, and receiving substrate. ${ }^{2}$ Nanosecond lasers with UV wavelength such as excimer laser $193 \mathrm{~nm}, 248$ $\mathrm{nm}$, or near UV wavelength such as $1064 \mathrm{~nm}$ are usually used as energy sources to obtain a pulse energy deposition with 1-20 $\mu \mathrm{J}$ per pulse. ${ }^{4,5}$ The ribbon is a multilayer component comprised of transparent glass, a thin layer of laser absorbing metal such as gold or titanium, and a suspended layer of the bioink that is composed of cells, hydrogels, and bioactive factors. When the laser beam pulses at a specified time duration that focuses on the ribbon, the metal layer on top of the hydrogel is vaporized, which will create a high-pressure bubble that ejects the bioink droplets onto the receiving substrate., ${ }^{6,7}$ The receiving substrate contains culture media to support growth after the cell droplets are transferred from the ribbon to the substrate. The resolution is defined as cells are printed successively in a continuous manner at desired coordinates. The LAB resolution varies from picometer to micrometer in size and depends on different factors such as the thickness of the bioink layer coated onto the ribbon, viscosity and surface tension of the bioink, wettability of the substrate, laser, an air gap between ribbon and substrate, and structural organization. ${ }^{4,8}$

$\angle A B$ has a high degree of precision and resolution that can print a high cell density ( 108 cells $\mathrm{mL}-1)$ and high viscosity (10-100 $\mu \mathrm{m})$ bioinks without imparting mechanical stress to the cells. ${ }^{9,10}$ Moreover, it can print individual cell or cell aggregates per droplet with high accuracy and cell viability. ${ }^{11-13}$

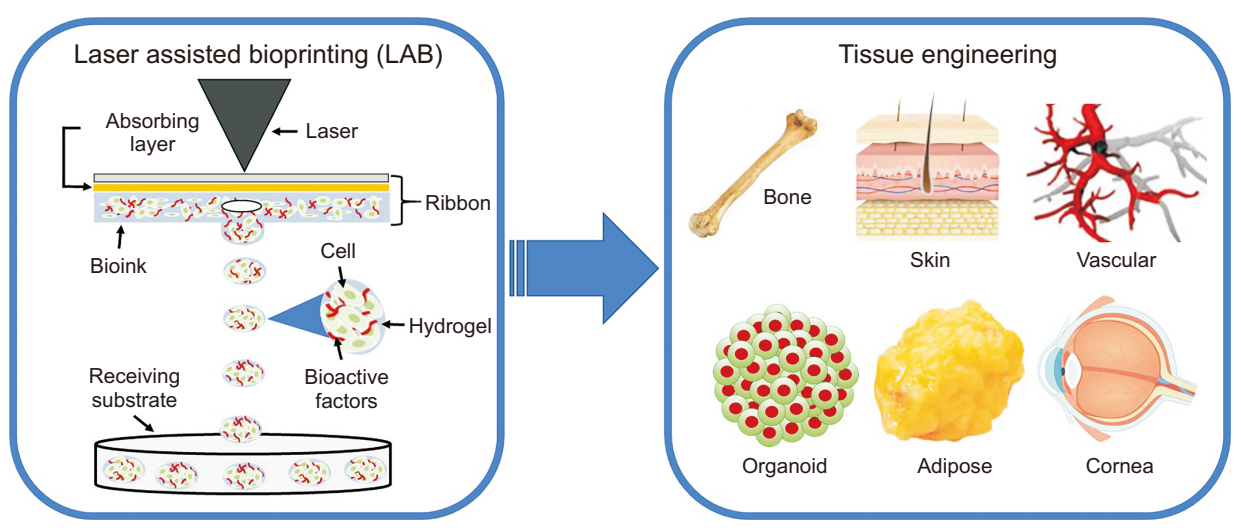

Fig. 1. Schematic diagram of Laser Assisted Bioprinting depicting its different parts. LAB can be used to fabricate different tissue constructs for tissue engineering applications. 


\section{BIOINK}

Bioink is one of the important factors for successive laser-assisted bioprinting. It is a combination of cells encapsulated in a biomaterial or combinations of different biomaterials in a hydrogel form. There are two kinds of bioinks currently used in bioprinting, scaffold-based consisted of a cell and a scaffold such as hydrogels, microcarriers, and decellularized matrix as a cell carrier and scaffold-free wherein no biomaterials were used as a cell carrier, only cell aggregates are printed directly. ${ }^{14}$

Stem cells are the most commonly used cells in bioprinting due to its versatility. These cells are pluripotent that can give rise to different cell types, has the ability of cell renewal or the ability to divide to make more cells, and fast proliferation making it an unlimited cell source for 3D bioprinting.

Different parameters should be considered in choosing materials for bioprinting. Ideal material should be biocompatible, material biomimicry, and appropriate mechanical and rheological properties to withstand bioprinting and degradation. ${ }^{15}$ Materials used as bioinks for the $L A B$ process are naturally derived polymers that have a closer resemblance to an extracellular matrix (ECM) and contain inherent bioactivity that supports cell function and proliferation such as collagen, gelatin, decellularized ECM, fibrin, and alginate. ${ }^{16}$

Collagen is the main component of the extracellular matrix making it an excellent biomaterial for cell growth and tissue regeneration. It offers a quick gelation rate under $\mathrm{pH} 8$ and a temperature of $37^{\circ} \mathrm{C} .{ }^{17}$ However, it has insufficient mechanical properties for load-bearing tissue engineering applications such as bone and cartilage. ${ }^{18}$ Synthetic and natural polymers are combined with collagen to improve its printability and its mechanical properties. $^{19}$

Gelatin is a fibrous protein derived from partial hydrolysis of collagen. ${ }^{20}$ It is a water-soluble and thermo-reversible that forms a hydrogel at a lower temperature $\left(<35^{\circ} \mathrm{C}\right)$ and turns viscous liquid at $37^{\circ} \mathrm{C}$ which is highly desirable for bioprinting. Moreover, it is biocompatible, has low antigenicity, biodegradable and low cost. ${ }^{21-23}$

Decellularized extracellular matrix (dECM) is a non-cellular component of tissues and organs. It mainly consists of collagen, glycosaminoglycans, growth factor, and other bioactive molecules making it biocompatible. ${ }^{24}$ It provides biochemical and biomechanical cues for cellular functions due to its inherent composition and characteristics. It is commonly combined with other natural and synthetic polymers to increase its mechanical properties. ${ }^{19}$
Fibrin is the main component of the blood clot and is a self-assembling natural polymer. It contains RGD (ArgGly-Asp), an amino acid sequence favorable in cell binding through cell integrin interactions. ${ }^{25}$ It is a biocompatible, biodegradable polymer that promotes cell attachment, proliferation, differentiation, and extracellular matrix formation. ${ }^{8,26}$

Alginate is a natural polysaccharide derived from brown seaweed. It is similar to the glycosaminoglycan of native ECM of the human body making it biocompatible and has ECM-like properties that allow cell encapsulation in a highly hydrated and mechanically suited 3D environment. Moreover, it is low cost, low toxicity, and has a fast gelation property under physiological conditions. ${ }^{27-30}$

\section{APPLICATION}

$L A B$ process provides a fabrication technique that can precisely control and replicate the internal structure as well as cellular orientation and arrangement of tissues, and organs such as bone, skin, cornea, organoid and adipose tissue.

\section{Bone}

LAB provides an improved vascularization and tissue integration in 3D bone-engineered constructs that enhanced bone formation specifically with a critical-sized or large bone defect. Keriquel et al. printed in situ mesenchymal stromal cells within the collagen and $\mathrm{nHA}$ matrix using LAB technology. After 1 and 2 months, a significant bone formation was observed on the defect site with the lab-printed constructs as opposed to the bare collagen and $\mathrm{nHA}$ matrix. ${ }^{31}$

\section{Skin}

Bio-printed skin enables accurate construction of tissue-engineered skin based on biomolecules and spatial arrangement of native skin. Michael et al printed 20 layers of fibroblast containing collagen and 20 layers of keratinocyte containing collagen onto a sheet of Matriderm ${ }^{\circledR}$ using the LAB method. The printed skin grafts were implanted into a full-thickness skin wound of a mouse. After 11 days, keratinocytes developed a dense stratified tissue synonymous with the normal epidermis with vascularization. ${ }^{32}$

\section{Cornea}

Cornea blindness due to corneal disease is one of the leading health problems faced by people in modern times. ${ }^{33}$ Bio-printed cornea enables researchers to fabricate and mimic the complex structure and cell-specific 
arrangement of the native cornea. Sorkio et al used the LAB method in fabricating the corneal mimicking structure. For epithelium mimicking structure, Human embryonic stem cell-derived limbal epithelial stem cells (hESC-LESC) were used as a cell source while human adipose tissue-derived stem cells (hASCs) were used for constructing layered stroma-mimicking structures. The 3D bio-printed stromal mimicking structures with hASC were implanted into an organ cultured porcine cornea. After 7 days in the porcine corneal organ medium, the 3D printed scaffold with hASC showed interaction and attachment to the host tissue. ${ }^{34}$

\section{Organoid}

Organoid fabricated in traditional method proved to be problematic and does not provide consistent microwell geometries that affect cell function and proliferation as well as insufficient vascularization. LAB process provides consistent high-density cell distribution with consistent microwell geometries and high resolution that enhanced vascularization. Gaebel et al. with the use of the LIFT method prepared a cardiac patch printed with HUVEC and human MSC (hMSC) in a defined pattern for cardiac regeneration. The cardiac patch was proved to enhance angiogenesis in the border zone of infarction and preserve cardiac functions after acute myocardial infarction in rats. ${ }^{35}$

\section{Adipose}

Human adipose-derived stem cells (hASCs) were printed using the LAB method in a free-scalable 3D grid pattern with alginate hydrogel on the substrate slide by Gruene et al. The hASCs proliferation and differentiation ability were not affected by the $L A B$ procedure. After 10 days, the $3 \mathrm{D}$ grafts were differentiated into the adipogenic pathway by the presence of visible lipid accumulation, and gene expression of adipogenic markers LPL, aP2, and PPAR- $\gamma 2$ from hASCs. ${ }^{36}$

\section{Vascular}

Printing of multiple cell types in a 3D array using the LAB technique was demonstrated by Gruene et al. Spots of human adipose-derived stem cells (ASCs) and endothelial colony-forming cells (ECFCs) with fibrin as cell carrier were arranged layer by layer in a 3D array. Results indicated that the cell viabilities of both cells were not affected by the laser-assisted printing procedure. After 2 weeks, vascular like structure formation was observed in a vascular endothelial growth factor (VEGF) free medium. ${ }^{37}$

\section{LIMITATIONS AND FUTURE PERSPECTIVE}

One of the limitations of $L A B$ setup is expensive for basic tissue engineering research. However, the cost of $3 \mathrm{D}$ printing technologies is rapidly decreasing due to higher supply and demand as the need for the fabrication of complex bioengineered tissue constructs are being in demand nowadays. Although laser-assisted bioprinting is highly desirable for printing highly viscous bioink with high cell viability and with great precision, it is still limited to printing $2 \mathrm{D}$ patterns due to its printing mechanism. Several studies have been fabricating a tubular 3D scaffold using the $L A B$ printing process and showed favorable results. ${ }^{30,38}$ Moreover, LAB can be utilized in combination with other $3 \mathrm{D}$ bioprinting methods or fabrication techniques to produce 3D tissue constructs with higher mechanical properties for tissue engineering applications.

$L A B$ process can print a combination of cells with high viability in one single spatial arrangement that mimics the orientation of native tissues and organs. It can generate artificial cell niches that are highly needed for cancer and drug research which cannot be fabricated using traditional methods. In addition, LAB fabricated constructs can be used in vitro for drug screening and toxicological testing as it provides complex structural and functional orientation similar to native tissues and organs of interest.

\section{CONFLICT OF INTEREST}

No potential conflict of interest relevant to this article was reported.

\section{FUNDING}

None.

\section{REFERENCES}

1. Arslan-Yildiz A, El Assal R, Chen P, Guven S, Inci F, Demirci U. Towards artificial tissue models: past, present, and future of $3 \mathrm{D}$ bioprinting. Biofabrication 2016;8:014103.

2. Guillemot F, Souquet A, Catros S, Guillotin B. Laser-assisted cell printing: principle, physical parameters versus cell fate and perspectives in tissue engineering. Nanomedicine (Lond) 2010:5:507-15.

3. Skardal A, Atala A. Biomaterials for integration with 3-D bioprinting. Ann Biomed Eng 2015;43:730-46.

4. Li J, Chen M, Fan X, Zhou H. Recent advances in bioprinting techniques: approaches, applications and future prospects. J Transl Med 2016;14:271. 
5. Guillemot F, Souquet A, Catros S, Guillotin B. Laser-assisted cell printing: principle, physical parameters versus cell fate and perspectives in tissue engineering. Nanomedicine (Lond) 2010;5:507-15.

6. Bishop ES, Mostafa S, Pakvasa M, Luu HH, Lee MJ, Wolf JM, et al. 3-D bioprinting technologies in tissue engineering and regenerative medicine: current and future trends. Genes Dis 2017;4:185-95.

7. Kačarević ŽP, Rider PM, Alkildani S, Retnasingh S, Smeets R, Jung 0, et al. An introduction to 3D bioprinting: possibilities, challenges and future aspects. Materials (Basel) 2018;11:2199.

8. Cui $X$, Boland T. Human microvasculature fabrication using thermal inkjet printing technology. Biomaterials 2009;30:62217.

9. Hopp B, Smausz T, Kresz N, Barna N, Bor Z, Kolozsvári L, et al. Survival and proliferative ability of various living cell types after laser-induced forward transfer. Tissue Eng 2005;11:1817-23.

10. Serra P, Fernández-Pradas JM, Colina M, Duocastella $M$, Domínguez J, Morenza JL. Laser-induced forward transfer: a direct-writing technique for biosensors preparation. J Laser Micro/Nanoeng 2006;1:236-42.

11. Kawecki F, Clafshenkel WP, Auger FA, Bourget JM, Fradette J, Devillard R. Self-assembled human osseous cell sheets as living biopapers for the laser-assisted bioprinting of human endothelial cells. Biofabrication 2018;10:035006.

12. Odde DJ, Renn MJ. Laser-guided direct writing of living cells. Biotechnol Bioeng 2000;67:312-8.

13. Barron JA, Wu P, Ladouceur HD, Ringeisen BR. Biological laser printing: a novel technique for creating heterogeneous 3-dimensional cell patterns. Biomed Microdevices 2004;6:13947.

14. Hospodiuk M, Dey M, Sosnoski D, Ozbolat IT. The bioink: a comprehensive review on bioprintable materials. Biotechnol Adv 2017;35:217-39.

15. Murphy SV, Atala A. 3D bioprinting of tissues and organs. Nat Biotechnol 2014;32:773-85.

16. Gungor-Ozkerim PS, Inci I, Zhang YS, Khademhosseini A, Dokmeci MR. Bioinks for 3D bioprinting: an overview. Biomater Sci 2018;6:915-46.

17. Diamantides N, Wang L, Pruiksma T, Siemiatkoski J, Dugopolski C, Shortkroff S, et al. Correlating rheological properties and printability of collagen bioinks: the effects of riboflavin photocrosslinking and $\mathrm{pH}$. Biofabrication 2017;9:034102.

18. Rhee S, Puetzer JL, Mason BN, Reinhart-King CA, Bonassar LJ. 3D bioprinting of spatially heterogeneous collagen constructs for cartilage tissue engineering. ACS Biomater Sci Eng 2016;2:1800-5.

19. Zhang Y, Kumar P, Lv S, Xiong D, Zhao H, Cai Z, et al. Recent advances in 3D bioprinting of vascularized tissues. Mater Des 2021;199:109398.
20. Hulmes DJ. Building collagen molecules, fibrils, and suprafibrillar structures. J Struct Biol 2002;137:2-10.

21. Elzoghby AO. Gelatin-based nanoparticles as drug and gene delivery systems: reviewing three decades of research. J Control Release 2013;172:1075-91.

22. Xing Q, Yates K, Vogt C, Qian Z, Frost MC, Zhao F. Increasing mechanical strength of gelatin hydrogels by divalent metal ion removal. Sci Rep 2014;4:4706.

23. Schuurman W, Levett PA, Pot MW, van Weeren PR, Dhert WJ, Hutmacher DW, et al. Gelatin-methacrylamide hydrogels as potential biomaterials for fabrication of tissue-engineered cartilage constructs. Macromol Biosci 2013;13:551-61.

24. Ventura RD, Padalhin AR, Park CM, Lee BT. Enhanced decellularization technique of porcine dermal ECM for tissue engineering applications. Mater Sci Eng C Mater Biol Appl 2019;104:109841.

25. Laurens N, Koolwijk P, de Maat MP. Fibrin structure and wound healing. J Thromb Haemost 2006;4:932-9.

26. Rajangam T, An SS. Fibrinogen and fibrin based micro and nano scaffolds incorporated with drugs, proteins, cells and genes for therapeutic biomedical applications. Int J Nanomedicine 2013;8:3641-62.

27. Sivashanmugam A, Arun Kumar R, Vishnu Priya M, Nair SV, Jayakumar R. An overview of injectable polymeric hydrogels for tissue engineering. Eur Polym J 2015;72:543-65.

28. Zhang Y, Yu Y, Akkouch A, Dababneh A, Dolati F, Ozbolat IT. In vitro study of directly bioprinted perfusable vasculature conduits. Biomater Sci 2015;3:134-43.

29. Jia J, Richards DJ, Pollard S, Tan Y, Rodriguez J, Visconti RP, et al. Engineering alginate as bioink for bioprinting. Acta Biomater 2014;10:4323-31.

30. Yan J, Huang Y, Chrisey DB. Laser-assisted printing of alginate long tubes and annular constructs. Biofabrication 2013;5:015002.

31. Keriquel V, Oliveira H, Rémy M, Ziane S, Delmond S, Rousseau $B$, et al. In situ printing of mesenchymal stromal cells, by laserassisted bioprinting, for in vivo bone regeneration applications. Sci Rep 2017;7:1778.

32. Michael S, Sorg H, Peck CT, Koch L, Deiwick A, Chichkov B, et al. Tissue engineered skin substitutes created by laser-assisted bioprinting form skin-like structures in the dorsal skin fold chamber in mice. PLoS One 2013;8:e57741.

33. Pascolini D, Mariotti SP. Global estimates of visual impairment: 2010. Br J Ophthalmol 2012;96:614-8.

34. Sorkio A, Koch L, Koivusalo L, Deiwick A, Miettinen S, Chichkov $B$, et al. Human stem cell based corneal tissue mimicking structures using laser-assisted 3D bioprinting and functional bioinks. Biomaterials 2018;171:57-71.

35. Gaebel R, Ma N, Liu J, Guan J, Koch L, Klopsch C, et al. Patterning human stem cells and endothelial cells with laser 
printing for cardiac regeneration. Biomaterials 2011;32:921830.

36. Gruene M, Pflaum M, Hess C, Diamantouros S, Schlie S, Deiwick $A$, et al. Laser printing of three-dimensional multicellular arrays for studies of cell-cell and cell-environment interactions. Tissue Eng Part C Methods 2011;17:973-82.

37. Gruene M, Pflaum M, Deiwick A, Koch L, Schlie S, Unger C, et al. Adipogenic differentiation of laser-printed 3D tissue grafts consisting of human adipose-derived stem cells. Biofabrication
2011;3:015005.

38. Xiong R, Zhang Z, Chai W, Huang Y, Chrisey DB. Freeform drop-on-demand laser printing of 3D alginate and cellular constructs. Biofabrication 2015;7:045011.

How to cite this article: Ventura RD. An overview of laserassisted bioprinting (lab) in tissue engineering applications. MedLasers2021;10:76-81.https://doi.org/10.25289/ML.2021.10.2.76 